\title{
Globalização, europeização e especificidade educativa portuguesa: A estruturação global de uma inovação nacional
}

Globalization, Europeanization and the Portuguese educational specificity: The global structuring of a national innovation

Globalisation, européennisation et particularité éducative portugaise : La structuration globale d'une innovation nationale

Fátima Antunes

\section{OpenEdition}

\section{Journals}

Edição electrónica

URL: http://journals.openedition.org/rccs/1051

DOI: $10.4000 /$ rccs. 1051

ISSN: 2182-7435

\section{Editora}

Centro de Estudos Sociais da Universidade de Coimbra

\section{Edição impressa}

Data de publição: 1 Dezembro 2004

Paginação: 101-125

ISSN: 0254-1106

Refêrencia eletrónica

Fátima Antunes, « Globalização, europeização e especificidade educativa portuguesa: A estruturação global de uma inovação nacional », Revista Crítica de Ciências Sociais [Online], 70 | 2004, colocado online no dia 01 outubro 2012, criado a 04 maio 2019. URL : http://journals.openedition.org/rccs/1051 ; DOI : 10.4000/rccs.1051 


\title{
Globalização, europeização e especificidade educativa portuguesa: A estruturação global de uma inovação nacional
}

\begin{abstract}
Neste trabalho exploram-se algumas relações entre os processos de globalização e a elaboração de políticas educativas nacionais. Procura-se compreender o modo como o processo de integração europeia constituiu um contexto relevante para a formulação de uma medida de política educativa - a criação do subsistema de Escolas Profissionais em Portugal em 1989. Esta inovação expressa ainda uma agenda política nacional para a educação atravessada por dilemas e, como procura mostrar-se, indubitavelmente inscrita nas condições, desafios e soluções que marcavam a realidade educativa portuguesa.
\end{abstract}

\section{Introdução}

São crescentemente visíveis, no campo da educação, alterações profundas cuja explicação torna indispensável o recurso a instrumentos teóricos desenvolvidos no contexto de debates sobre fenómenos analisados como processos de globalização. ${ }^{1}$ Alguns autores, como Boaventura de Sousa Santos (1997, 2001a), têm defendido que estamos perante dinâmicas multidimensionais, heterogéneas, arrítmicas e assimétricas que apontam para múltiplos modos de produção e formas de globalização. ${ }^{2}$ No domínio da análise científico-social da educação, têm sido desenvolvidas duas linhas de investigação principais que procuram apreender as novas configurações assumidas pelos fenómenos educativos num contexto de alteração e intensificação das arti-

\footnotetext{
${ }^{1}$ Este texto tem por base uma pesquisa que decorreu entre 1996 e 2002, tendo sido, até 1999, integrada no projecto "A sociedade portuguesa perante os desafios da globalização: modernização económica, social e cultural", desenvolvido no Centro de Estudos Sociais da Universidade de Coimbra e financiado pelo programa Praxis XXI; esta investigação beneficiou também, durante todo o período da sua realização, do apoio do Centro de Estudos em Educação e Psicologia da Universidade do Minho.

2 Para uma análise, ainda que significativamente divergente da desenvolvida pelo autor acima referido, que igualmente sublinha o carácter multifacetado, heterogéneo e assimétrico dos processos de globalização, cf. Giddens (1992, 2000).
} 
culações e conexões entre processos que ocorrem às escalas global/supranacional e nacional. Dispomos, por um lado, de um conjunto de estudos que enfatiza a difusão mundial de padrões de organização da educação escolar, como parte de um processo de globalização cultural de longa duração (em paralelo com a expansão da forma política do Estado-nação); neste contexto, são sublinhadas a penetração de ideologias e a institucionalização de modelos educativos largamente estandardizados, tendo como principais actores, nas últimas décadas, as organizações internacionais (OCDE, UNESCO, Banco Mundial, entre outras). ${ }^{3}$ Mais recentemente, e no campo da sociologia das políticas educativas, tem vindo a afirmar-se uma proposta teórica que defende que as tendências em curso são analisáveis como parte de uma agenda globalmente estruturada para a educação; neste sentido, procura-se construir uma problemática capaz de explicar quer a especificidade dos processos nacionais, quer as suas interacções (mais ou menos intensas, mediadas ou difusas) com dinâmicas transnacionais e globais (Dale, 1999, 2000a, 2000b; Antunes, 2001).

O estudo que a seguir se apresenta procura articular criticamente as potencialidades heurísticas das duas abordagens e beneficiar delas. Assim, mobilizaremos a perspectiva de uma agenda globalmente estruturada para a compreensão de alguns desenvolvimentos políticos recentes no campo da educação. Nesse contexto, analisaremos o impacto e influência de entidades como a Comunidade/União Europeia no domínio educativo, a interpenetração de políticas nacionais e comunitárias, a difusão/apropriação de orientações e modelos; a abordagem adoptada exclui, no entanto, a uniformização de processos e resultados como corolário necessário de tais dinâmicas. Nesse sentido, a difusão de categorias cognitivas, ideologias e modelos institucionais ${ }^{4}$ - sendo entendida como parte de processos de transnacionalização e globalização em curso no campo da educação - não assume um papel determinante na análise; é tratada como interagindo com outros fenómenos, que medeiam, especificam e refractam os resultados possíveis e é contemplada como contexto, como móbil, como terreno e objecto da acção protagonizada, em cada processo concreto, pelas instâncias e actores nacionais e internacionais.

\footnotetext{
3 Alguns dos estudos desenvolvidos neste âmbito podem ser encontrados, por exemplo, em Ramirez e Boli (1987); Meyer et al. (1992). Para uma discussão alargada desta perspectiva, ver Schriewer (1996) e Apple (1996: 129); para uma crítica aprofundada e um confronto com a hipótese, a seguir referida, de uma agenda globalmente estruturada para a educação, consultar Dale (2000a, 2000b) e verificar ainda Gomes (2001). O estudo da influência das organizações internacionais na política educativa portuguesa é desenvolvida por Teodoro (2001a, 2001b).

${ }^{4}$ Esse processo chega, segundo António Teodoro, a assumir actualmente a forma de fixação de uma agenda global (Teodoro, 2001a).
} 


\section{A União Europeia e a elaboração de políticas educativas nacionais}

Uma das mudanças contemporâneas mais salientes, no domínio das relações económicas e políticas, é a emergência de um novo protagonismo por parte de blocos e entidades de carácter regional associados à importância crescente assumida por instituições internacionais com uma existência mais ou menos duradoura. ${ }^{5}$ As organizações regionais têm sido analisadas como entidades supranacionais fundadas com base em acordos multilaterais entre Estados e cuja actuação simultaneamente medeia e contribui fortemente para o desenvolvimento de dinâmicas de globalização e dos seus efeitos; constituem, assim, instâncias que criam, modelam, filtram e veiculam esses processos (Dale e Robertson, 2000).

A União Europeia representa uma das formas institucionais mais avançadas neste domínio, desenvolvendo um vasto âmbito de intervenção e assumindo progressivamente um papel mais activo (em sentidos divergentes e com resultados diversificados) na área das políticas sociais.

Dada a associação estreita entre os processos que referimos e a emergência de novas formas de actuação do Estado com impacto decisivo naquela área de acção, torna-se necessário examinar as relações entre o denominado processo de integração europeia e a elaboração das políticas educativas nacionais. Na senda de diversos investigadores, condensamos aquele vasto leque de modalidades de intervenção pública sob as noções de Estado de competição, Estado-em-rede e Estado-articulador as quais, embora de modo imperfeito e insatisfatório, pretendem dar conta de formas específicas de acção estatal que podem surgir singularizadas ou combinadas em determinadas áreas da vida social. O Estado parece, assim, envolvido em transformações que apontam para três configurações ou formas de actuação parciais fundamentais: o Estado de competição (competition state), cujas prioridades se orientam para a actuação em instâncias supranacionais e para a intervenção no plano nacional de modo a promover a competitividade da sua economia e a expandir as oportunidades de acumulação (Cerny, 1990: 53 , 205, 220ss.); o Estado em rede (the network state), enquanto articulação de segmentos de Estados que asseguram a intervenção em áreas da vida social cujo controlo escapa às fronteiras da soberania nacional (Castells, 1997: 266-9, 1998: 331, 350-2, 366-7, 375); e o Estado-articulador, voltado para a criação de condições de mediação dos interesses sociais, sob novas fórmu-

\footnotetext{
${ }^{5}$ As organizações regionais mais importantes são hoje a UE (União Europeia), a NAFTA (Associação Norte Americana de Comércio Livre) e a APEC (Fórum de Cooperação Económica da Ásia-Pacífico); entre as organizações internacionais mais relevantes contam-se a ONU (Organização das Nações Unidas), o BM (Banco Mundial), o FMI (Fundo Monetário Internacional), a OMC (Organização Mundial do Comércio), a OCDE (Organização para a Cooperação e Desenvolvimento Económico).
} 
las e arranjos institucionais de que não é o único nem o principal protagonista (Santos, 1998: 59-69, 1999: 38-9). ${ }^{6}$

A perspectiva de uma agenda globalmente estruturada para a educação admite, com base em estudos de economia política, que os Estados-nação se confrontam com "um conjunto sistemático de questões", colocadas quer pelos processos de globalização (económicos, políticos, culturais), quer pela situação desses mesmos Estados no contexto internacional que condiciona a sua relação com aqueles processos (Dale, 2000b: 428). O referido conjunto sistemático de questões pode ser relacionado com o modo como são configurados os problemas centrais frente aos quais se constitui a agenda do Estado nas formações sociais capitalistas: o apoio ao processo de acumulação; o favorecimento de um contexto que não iniba a sua expansão continuada e a legitimação do sistema e do papel do Estado (Dale, 1988, 2000b). Num contexto económico-político globalizado, tais problemas recaem no campo de actuação quer de instituições políticas supranacionais e regionais, como a União Europeia, quer dos Estados nacionais, ainda que as fortes relações vislumbradas entre as soluções adoptadas nos diferentes níveis estejam longe de permitir concluir no sentido da sua coerência, complementaridade ou articulação sistemáticas.

O argumento principal da perspectiva de uma agenda globalmente estruturada para a educação é sustentado pela análise de que o modo como aqueles problemas se apresentam e a prioridade relativa que lhes é atribuída são crescentemente modelados pelos constrangimentos e pressões de relações globais (sobretudo económico-políticas), dispondo os Estados de um leque diminuído de opções quanto à orientação das suas políticas. Tal não implica que a actuação do Estado seja determinada pelo contexto económico-político global/regional, mas as orientações adoptadas e os processos sociais implementados serão o resultado da interacção complexa entre a percepção/ interpretação e formulação daqueles problemas pelos actores do Estado, da sociedade civil e da economia e o leque de respostas e soluções disponibilizáveis através das instituições existentes ou possíveis a partir dos recursos políticos, económicos e culturais mobilizáveis no contexto nacional. Desse modo, os efeitos mais importantes dos processos de globalização na educação decorrem de alterações concomitantes no modo de regulação ${ }^{7}$

\footnotetext{
${ }^{6}$ Discutimos algumas destas metamorfoses recentes na organização (e luta) política em Antunes (2004: 81-88).

${ }^{7}$ Este conceito, desenvolvido pela Escola da Regulação francesa, põe em relevo que a trama de instituições que favorecem a congruência dos comportamentos individuais e colectivos e medeiam os conflitos sociais chega a produzir as condições para a estabilização (sempre temporária e dinâmica, ainda que prolongada) de um dado regime de acumulação (cf. Boyer, 1987: 54-5, 1997: 3; Aglietta, 1997: 412, 429; cf. ainda Antunes, 1998: 30-2).
} 
particular das formações sociais nacionais e na natureza, funcionamento e papel em mudança assumidos pelos Estados-nação como resposta e no contexto daqueles fenómenos (Dale, 1999: 1-5, 2000a: 99-101, 2000b).

Discutiremos a questão da relação entre o processo de integração europeia e a elaboração de políticas educativas nacionais investigando, num primeiro momento e através de diferentes olhares, o modo como a educação tem sido considerada e definida no contexto comunitário e as possíveis implicações desses processos para os sistemas de ensino dos Estados-membros. ${ }^{8}$ Num segundo momento, o processo de criação e desenvolvimento de um subsistema de Escolas Profissionais em Portugal, a partir de 1989, é examinado à luz de algumas perspectivas e interpretações teóricas disponíveis sobre a configuração das políticas públicas (educativas) nacionais no quadro da (então) Comunidade (Económica)/União Europeia. Na última parte do texto, discutiremos ainda o significado daquela medida política, identificando alguns vectores da agenda política nacional para a educação, no período em questão.

\subsection{A educação no contexto comunitário (1971-1992)}

Sugerimos em outros trabalhos que é visível, nas últimas décadas, o desenvolvimento de dois processos interligados quanto ao modo como a educação tem sido considerada no contexto da Comunidade/União Europeia (cf. Antunes, 1999a). Por um lado, assistimos à institucionalização e consolidação da educação como área de cooperação e acção e, posteriormente, de intervenção política comunitária; por outro lado, emerge e intensifica-se a construção de entendimentos, orientações e normas de acção comuns para as políticas educativas nacionais dos Estados-membros. Assim, com base na análise dos documentos (resoluções, conclusões, decisões e directivas) saídos das reuniões do Conselho Europeu e dos Ministros da Educação, reunidos no seio do Conselho, entre 1971 e 1992, e publicamente divulgados, é possível defender que a longa fase anterior à aprovação do Acto Único Europeu em 1986 se caracteriza por uma dinâmica de inovação, em construção progressiva, desenhada e consolidada com base no estabelecimento de agendas e prioridades comuns aos Estados-membros na esfera

\footnotetext{
${ }^{8}$ Analisaremos apenas o período entre 1957 (data em que foi assinado o Tratado de Roma, fundador da Comunidade Económica Europeia) e 1992, dado o nosso interesse particular em compreender o contexto em que teve lugar a criação do subsistema de Escolas Profissionais em Portugal, em 1989. A educação emerge como campo de acção ao nível comunitário, em 1971, com a criação pela Comissão Europeia, de dois grupos de trabalho (um para o Ensino e Educação e outro para a Coordenação); no mesmo ano, ocorre um primeiro encontro dos Ministros da Educação; a este primeiro impulso segue-se, durante alguns anos, um conjunto de iniciativas bastante irregulares, cuja análise pode ser encontrada em Rodriguez (1993), Beukel (1993) e Antunes (1999a).
} 
da educação, assente na cooperação intergovernamental e processos normativos; no período seguinte, entre 1986 e 1992, é já de realçar o estabelecimento de uma agenda e políticas comunitárias para a educação, sustentadas em acções comunitárias e processos normativos (intensificados). ${ }^{9}$ A emergência de múltiplas relações (funcionais e) de (inter)dependência crescentes entre a elaboração das políticas (nacionais e comunitárias) e as prioridades e instituições comunitárias evidencia o despontar de um processo crescentemente vincado de europeização da educação no contexto comunitário, nomeadamente após 1986 (Antunes, 1999a). Tal significa, basicamente que é possível identificar dimensões da intervenção política pública em educação em que as instituições da Comunidade/União Europeia e os sistemas políticos nacionais podem ser vistos como tendendo a constituir uma totalidade (Andersen e Elliassen, 1993a, 1993b), não forçosamente integrada ou isenta de conflitos, mas, pelo contrário, consideravelmente fragmentada, difusa e contraditória.

Argumentámos ainda que, entre meados da década de setenta e o início da década de noventa, e no contexto de instituições comunitárias como o Conselho Europeu, teve lugar a construção e explicitação de um conjunto de entendimentos e orientações comuns aos Estados-membros tendentes a estabelecer uma matriz discursiva que redefine a educação em torno de um conjunto de vectores ou pólos discursivo-ideológicos:

(i) a redefinição do processo e das instituições educativos promovendo novas relações, no seio da educação, com o mundo produtivo e de trabalho;

(ii) a ênfase na diferenciação de dispositivos de integração, no interior das instituições, e a promoção da possibilidade de escolha e da diversificação da oferta de bens e serviços educativos, reconstituindo, em novos moldes, as bases e as modalidades de concretização da cidadania educativa;

(iii) a introdução de novas dimensões na articulação entre as instituições educativas e o mundo público e privado, sublinhando este como locus de promoção do Bem Comum;

(iv) o encorajamento de dinâmicas que potenciem a emergência de novas configurações e princípios para a organização de sistemas, redes e/ou mercados de educação e formação de âmbito comunitário (Antunes, 1999b).

\footnotetext{
9 A identificação de processos normativos é fundada na noção apresentada por Yasemin Soysal para referenciar a elaboração e difusão entre os Estados-membros de princípios, modelos e formas institucionais através do seu envolvimento em modalidades diversas de interacção e acção cooperativa transnacional (Soysal, 1993).
} 
Defendemos que a elaboração de um tal quadro, ainda que difuso, constitui uma modalidade específica de promoção/modelação de processos de globalização no âmbito desta organização regional; isto porque, por um lado, aquelas orientações são susceptíveis de constituir um referencial global europeu traduzido por normas de acção comuns que vão influenciar os processos de produção de políticas nacionais e comunitárias; ${ }^{10}$ por outro lado, as formas de actuação do Estado em rede, do Estado de competição e do Estado-articulador, emergentes no contexto das transformações ocorridas nas últimas décadas, são desenhadas através das mudanças propostas.

\subsection{O subsistema de escolas profissionais em Portugal: uma inovação congruente com um referencial global europeu para a educação}

\subsubsection{Uma breve contextualização}

O sistema educativo português apresenta-se, no final dos anos 80, como um serviço público com marcadas características de subdesenvolvimento, dados os níveis de cobertura da população que é capaz de proporcionar, quer dos pontos de vista quantitativo (taxa de frequência), quer qualitativo (taxa de sucesso nas aprendizagens e de distribuição de diplomas).

O diagnóstico elaborado pela administração central, como base da proposta à União Europeia (então Comunidade Económica Europeia) do Programa de Desenvolvimento Educativo para Portugal (1990-1993) (PRODEP I), é, a esse título, elucidativo: "a taxa de escolarização da população portuguesa no primeiro nível $(90 \%)$ é comparável com a dos outros países, mas a do segundo nível já é cerca de metade da média dos outros membros da comunidade e a do terceiro nível ou do ensino superior é ainda menos de metade da média desses países" (com base em dados de 1987). Assim, em 1987/88, verificam-se as seguintes taxas de escolarização: educação pré-escolar, 30\%; ensino básico ( $1^{\circ}$ ciclo, 100\%; $2^{\circ}$ ciclo, $90 \%$ ); ensino secundário, 40\%; ensino superior, $11 \%$ (cf. Gabinete de Estudos e Planeamento/Ministério de Educação, 1990: 28, 37). ${ }^{11}$

\footnotetext{
${ }^{10}$ A análise que identifica um referencial global europeu para as políticas educativas públicas nacionais é inspirada na perspectiva desenvolvida por Mény et al. (1995). António Nóvoa, num trabalho que constitui o primeiro estudo que conhecemos em Portugal sobre a intervenção da Comunidade/União Europeia no domínio da educação, chama a atenção para a "longa lista de documentos que definem orientações ao mesmo tempo em que constroem uma linguagem para falar da educação na Europa" pondo em realce a importância dos discursos para a definição e sustentação das políticas nacionais e comunitárias e defendendo, consequentemente, a necessidade da sua análise (Nóvoa, 1998: 97-111; sublinhados no original).

${ }^{11}$ Nesta data, o ensino básico obrigatório compreendia apenas seis anos e o ensino secundário abrangia os dois ciclos seguintes. A Reforma do Sistema Educativo traduziu-se, neste domínio, pelo prolongamento da escolaridade obrigatória para nove anos e a circunscrição do ensino secundário aos $10^{\circ}, 11^{\circ}$ e $12^{\circ}$ anos.
} 
Neste contexto, a criação das Escolas Profissionais em 1989 configura-se como uma medida a vários títulos singular: é elaborada e implementada no âmbito de uma Reforma Educativa, destacando-se, dado que foi a primeira medida incluída nos estudos da Comissão de Reforma do Sistema Educativo a ser generalizadamente concretizada e autonomizando-se simultaneamente pelo recurso a procedimentos únicos na sua realização. ${ }^{12}$ Sendo possível estabelecer um laço temporal com as outras medidas adoptadas para o ensino/formação de nível secundário, e que conjuntamente vêm a reestruturar este sector de ensino, as Escolas Profissionais aparecem, no entanto, com a particularidade de ser a medida mais inovadora a vários títulos e que mais rápida e completamente é implementada. ${ }^{13}$

A sua criação em 1989, incorpora e condensa alguns dos principais problemas, dilemas e soluções experimentados nas políticas educativas (e sociais) nos últimos anos em Portugal: aparecem como instituições impulsionadas pelo Estado, mas apresentadas como uma aposta na iniciativa da sociedade civil, sob a forma de parcerias locais ou sectoriais; pretendem cumprir um programa de diversificação da educação que permita a escolha entre modalidades de formação, sendo orientadas para um público escolar definido; integram modalidades de aproximação aos contextos de trabalho e dispositivos de transição profissional; ${ }^{14}$ por último, surgem geralmente com o estatuto de escolas privadas, quase totalmente financiadas através de recursos públicos e desenvolvidas, em grande parte dos casos, com base em, ou com a participação de, organismos públicos da administração central e local (Câmaras Municipais, por exemplo) e de organizações referenciáveis ao terceiro sector (instituições de solidariedade social, sindicatos, associações...).

\footnotetext{
12 Para uma mais ampla compreensão deste processo, consultar Afonso (1998), que desenvolve a análise mais abrangente e aprofundada que conhecemos sobre a Reforma do Sistema Educativo Português nos anos 80 em Portugal. O estudo apresentado por Lima (1998) sobre "a administração do sistema educativo e das escolas" constitui igualmente uma referência nesta área.

${ }^{13}$ São contemporâneas da implementação de um subsistema de Escolas Profissionais, em 1989, as seguintes medidas: abertura de cursos de Aprendizagem em alternância, concedendo um certificado de qualificação profissional de nível III com equivalência ao $12^{\circ}$ ano (criados em 1988, entram em funcionamento apenas em 1991); a reforma curricular do ensino secundário regular, em 1989, com entrada em vigor a partir de 1990/91, instaurando Cursos Predominantemente Orientados para o Prosseguimento de Estudos (Cursos Gerais) e Cursos Predominantemente Orientados para o Ingresso na Vida Activa (Cursos Tecnológicos). Deste modo, o ensino/formação de nível secundário está hoje (2004) organizado em quatro segmentos. Diferentes análises destas medidas podem ser encontradas em, Stoer et al. (1990); Grácio (1998a, 1998b), Antunes (2000a, 2000b).

${ }^{14}$ Uma proposta de análise da organização da transição profissional é desenvolvida por Rose (1984, 1996).
} 


\subsubsection{Uma inovação congruente com um referencial global europeu}

O estudo do processo de formulação e implementação do subsistema de Escolas Profissionais permitiu identificar alguns traços marcantes que, no contexto desta análise, nos limitaremos a sinalizar. ${ }^{15}$ Assim, esta inovação orienta-se para a redefinição do processo e das instituições educativos pretendendo favorecer de múltiplas formas as interacções entre os contextos de trabalho e os contextos escolares. Também a modalidade de governação ${ }^{16}$ estabelecida para o subsistema, assente em parcerias e contratos-programa, exibe uma orientação político-ideológica que elege o privado como locus de promoção do bem comum assentando numa reformulação das prioridades da acção pública; estas rearticulações, características da forma de actuação do Estado de competição, conduzem à subalternização das preocupações de legitimação para valorizar a criação de condições favoráveis à expansão do processo de acumulação. Aquela modalidade de governação proposta para as Escolas Profissionais releva ainda de um outro conjunto de mudanças nas relações sociais com incidência no papel do Estado que Santos condensou sob a fórmula de Estado-articulador (Santos, 1998). ${ }^{17}$

No contexto da criação do subsistema de Escolas Profissionais, a cidadania educativa é modulada pela expansão controlada de oportunidades permitida pela diversificação de modalidades de escolarização orientada para populações específicas. Por outro lado, as Escolas Profissionais parecem ter beneficiado de uma ligação particularmente intensa a parcerias transnacionais e deter condições e características de natureza institucional que encorajam a participação em dinâmicas favoráveis ao estabelecimento de sistemas, redes e/ou mercados de educação e formação de âmbito comunitário; sugerimos que estes movimentos induzem e requerem modalidades de regulação das relações sócio-políticas envolvidas com a forma de actuação de Estado em rede.

Parece, assim, ser possível defender que a análise da criação do subsistema de Escolas Profissional em Portugal em 1989 permite verificar múlti-

\footnotetext{
${ }^{15}$ Uma apresentação mais desenvolvida deste estudo pode ser encontrada em Antunes (2001, 2004).

${ }^{16} \mathrm{O}$ conceito de governação remete, neste contexto, para a combinação de formas de coordenação adoptadas para as actividades de financiamento, fornecimento e regulação implicadas pela provisão desta modalidade de serviço educativo (cf. Dale, 1997; Antunes, 2001).

${ }_{17}$ A governação implementada no subsistema de Escolas Profissionais tem sido objecto de alterações, nomeadamente em 1998, estando em curso a experimentação de um novo esquema de financiamento no presente ano lectivo (2003/04) para as escolas da região de Lisboa e Vale do Tejo. A análise destas mudanças não será aqui desenvolvida; para uma discussão destas questões cf. Antunes (2003).
} 
plas congruências entre a agenda para a educação promovida em instâncias da Comunidade/União Europeia e as direcções imprimidas a essa inovação sócio-política. As linhas de força daquele referencial global europeu evidenciam a formulação de orientações para a acção pública que corporizam formas de actuação do Estado associadas a alterações do modo de regulação produzidas por processos e relações globais em curso. A matriz discursiva de definição da educação atrás identificada constitui, assim, simultaneamente, uma cristalização provisória e situada e um factor constituinte da agenda globalmente estruturada para a educação em que se inscreve a medida de política educativa portuguesa estudada.

\subsection{A interpenetração de políticas (educativas) nacionais e comunitárias: dinâmicas de europeização}

\subsubsection{A especificidade educativa portuguesa e a articulação de políticas}

A criação das Escolas Profissionais em 1989 constitui uma medida de política educativa cuja elaboração e concretização parecem inseparáveis da integração de Portugal na (então) Comunidade Europeia. Desde logo, alguns dos responsáveis políticos e técnicos do GETAP ${ }^{18}$ realçam esta quase filiação, inscrita nos aspectos mais políticos e ideológicos (relativos a orientações crescentemente influentes e a prioridades intensamente sublinhadas, no contexto comunitário, no que toca ao ensino e formação profissional pós-obrigatórias dos jovens), com forte e inegável incidência nas questões mais pragmáticas de canalização de fundos e financiamento de iniciativas.

Não encontramos unanimidade nos principais agentes estatais no que toca à origem da política, sobretudo em relação aos aspectos considerados como mais relevantes. Uns enfatizam o enraizamento profundo dos pressupostos e concepções fundadoras de tal medida em perspectivas comuns e então em ascensão na Comunidade (Marques, 1993: 25-719); outros inscrevem a elaboração da política em convicções partilhadas pelos seus responsáveis, referindo a ligação à Comunidade Europeia, no que toca à coincidência de prioridades para o ensino/formação profissional de jovens, com papel facilitador fundamental quanto à viabilização financeira de tal medida. Joaquim Azevedo identifica esta relação, circunscrevendo,

\footnotetext{
${ }^{18}$ Gabinete de Educação Tecnológica, Artística e Profissional, organismo do Ministério da Educação criado pelo Decreto-lei no 397/88 de 9 de Novembro, equiparado a Direcção-Geral e responsável pela implementação do subsistema de Escolas Profissionais.

${ }_{19}$ Margarida Marques foi vice-directora do GETAP.
} 
mas enfatizando, a ligação funcional entre as concepções e prioridades políticas comunitárias e a orientação e concretização de medidas no contexto nacional:

É assim, porque as Escolas (Profissionais) [...] foram pensadas e estruturadas totalmente independentes do PRODEP, o PRODEP veio depois. O PRODEP introduz-se aqui como o instrumento de financiamento, aliás o PRODEP foi montado para isso. [...] é construído porque é preciso arranjar mecanismos de financiamento [...] comunitário para determinados subsectores do sistema de educação [...] e portanto captar fundos comunitários para fazer engrossar o orçamento de Estado para desenvolver certas áreas específicas que era possível apoiar através do FEDER e do Fundo Social Europeu [...] E uma das beneficiadas nesse caso, uma das perspectivas que estava a ser avançada e que beneficiou foram as Escolas Profissionais que estavam no terreno e houve ali aquele momento em uníssono, tudo apareceu mais ou menos em simultâneo. ${ }^{20}$

Aliás, esta ligação, entre políticas e prioridades ao nível da Comunidade/ União Europeia e intervenções do Estado no sistema educativo português, parece ter sido crucial, em vários sentidos, permitindo ou reforçando, viabilizando ou dissuadindo, a definição e concretização de orientações. Mas, a relação entre a Comunidade Europeia e a política educativa portuguesa, nomeadamente a criação das Escolas Profissionais, não parece reduzir-se à viabilização ou inibição de intervenções políticas definidas pelo Estado nacional. Poderia falar-se também de indução ou criação de condições que, directa ou indirectamente, conduzem ao surgimento de determinadas opções políticas nacionais. Assim, o facto de, subitamente, Portugal, ainda antes da elaboração e aprovação do PRODEP I, dispor de um fluxo de financiamentos avultados para o ensino/formação profissional pós-obrigatória dos jovens, enquanto, em simultâneo, não existia um sistema estruturado para o efeito, no âmbito dos ministérios do Emprego ou da Educação, pode ter-se configurado como um incentivo importante para a elaboração de medidas políticas capazes de aproveitar tais meios. ${ }^{21}$

\footnotetext{
${ }^{20}$ Entrevista concedida por Joaquim Azevedo, Director do GETAP entre 1988 e 1992, à autora, no âmbito desta pesquisa, em 22 de Julho de 1997.

O PRODEP é o Programa de Desenvolvimento Educativo para Portugal apoiado pela Comunidade Europeia, através dos Fundos Estruturais, entre 1990-1993 (PRODEP I); 1994-1999 (PRODEP II) 2000-2006 (PRODEP III). O FEDER é um dos fundos estruturais da União Europeia, Fundo de Desenvolvimento Regional.

${ }_{21}$ Margarida Marques descreve desta forma alguns dos momentos que conduziram à criação das Escolas Profissionais: "há em Agosto de oitenta e oito [1988] prazos para a publicação de candidaturas de projectos para financiamento do Fundo Social [...] e na altura o Roberto Carneiro
} 
E não deve ser ignorado que o figurino institucional concebido para as Escolas Profissionais era de molde a permitir o financiamento das acções de formação e formadores, já que se tratava de instituições exteriores ao sistema de ensino regular, cujos cursos, professores e funcionários são definidos como de exclusiva responsabilidade do Estado nacional recaindo fora do âmbito de intervenção comunitária. Se aquela exterioridade institucional das Escolas Profissionais relativamente ao sistema educativo regular é fundada nas prioridades e âmbito de acção da Comunidade Europeia, ou apenas congruente com eles, é uma discussão que, com os dados disponíveis, não pode ser aqui concludentemente resolvida. No entanto, uma indicação é possível reter: as Escolas Profissionais emergem em simultâneo com a possibilidade de acesso a financiamentos comunitários para o ensino e formação profissional de jovens cuja utilização era possível apenas em contextos institucionais e segundo modalidades, exteriores ao sistema educativo regular, compatíveis com as competências e âmbito de acção comunitários. Ainda que tal contexto possa não ter sido determinante na definição concreta das opções políticas particulares que configuram as Escolas Profissionais, foi certamente uma condicionante fortíssima indutora de algumas orientações já que, objectivamente, inibia outras - por exemplo, a concentração dos recursos financeiros no desenvolvimento do ensino profissional no âmbito do sistema regular não superior.

Ainda uma breve reflexão no que toca ao PRODEP, programa que tem garantido o financiamento quase total do subsistema de Escolas Profissionais. ${ }^{22} \mathrm{O}$ primeiro Programa de Desenvolvimento Educativo para Portugal (1990-1993) representa uma iniciativa interessante da parte do Estado português que, apesar de os sistemas educativos nacionais serem considerados da exclusiva competência dos Estados-membros, propôs a canalização de avultadas somas, do Fundo de Desenvolvimento Regional e do Fundo Social Europeu, para o sistema de ensino. Os condicionalismos, limitações e ambiguidades permitidos por relações de (inter)acção e (inter)dependência entre os sistemas e intervenções políticos nacionais e comunitários são bem evidentes neste processo. Por um lado, a política

pediu-me [...] para preparar até ao dia 15 de Agosto um projecto de criação, de financiamento para a criação de Escolas Profissionais [... ] foi objecto de um despacho especial para que o projecto pudesse ser adoptado [...] previa, eu penso que era a criação de 20 escolas e portanto financiadas pelo FSE, portanto era um projecto FSE [...] aí aparece, digamos, o suporte financeiro para a criação das escolas [...] vinte mil alunos, nós não propúnhamos escolas, propúnhamos alunos" (Margarida Marques em entrevista concedida à autora, no âmbito desta pesquisa, em 29 de Julho de 1997).

${ }^{22}$ O financiamento público do subsistema de Escolas Profissionais foi garantido em $75 \%$ por verbas de origem comunitária, disponibilizando o Estado português os restantes $25 \%$. 
comunitária de promoção da coesão social, através da constituição de Fundos Estruturais a serem canalizados para os Estados-membros, permitiu ao Estado português fazer abranger a viabilização de algumas políticas educativas através de financiamentos comunitários, inscrevendo-as e referenciando-as a prioridades e orientações políticas prevalecentes na Comunidade Europeia: a coesão social e a qualificação dos recursos humanos. ${ }^{23}$ Por outro lado, como argumentámos anteriormente, as opções e prioridades políticas prevalecentes no plano comunitário têm um efeito selectivo forte, quer induzindo directamente, quer criando um contexto indutor da orientação no sentido de determinadas intervenções, quer reforçando e viabilizando algumas políticas e inibindo ou tendo um papel dissuasor no desenvolvimento de outras.

Desta forma, o processo de fundação do subsistema de Escolas Profissionais parece dever ser inscrito em dinâmicas de europeização das políticas (educativas) públicas nacionais: por um lado, é possível identificar relações de interacção e interdependência significativas entre prioridades e opções políticas comunitárias e a criação de um contexto fortemente indutor de algumas das orientações que caracterizam tal medida política; por outro lado, a sua viabilização, nomeadamente financeira, parece decisivamente devedora da coincidência entre concepções e finalidades incorporadas nesse sector de ensino e linhas de intervenção valorizadas no âmbito das políticas comunitárias.

Nesse sentido, admitir a hipótese de uma "totalidade", entre as instituições e políticas da Comunidade/União Europeia e a elaboração das políticas nacionais, relativamente a alguns processos, dimensões e vectores, torna possível realçar a importância decisiva do contexto comunitário na afirmação e realização de algumas opções, bem como na subalternização de outras orientações possíveis por parte dos Estados-membros. Tal "totali-

${ }^{23}$ Como se argumenta na proposta do Programa de Desenvolvimento Educativo para Portugal (1990-1993) (PRODEP I): “Portugal não pode, sozinho, desenvolver um conjunto de empreendimentos de tão grandes proporções como os que o PRODEP inclui. Daí que seja necessária a mobilização dos fundos estruturais da Comunidade para resolver um problema que é fundamentalmente um problema comunitário posto que se trata de promover a coesão económica e social entre as várias regiões.

Os regulamentos dos fundos estruturais foram concebidos para uma comunidade que em grande parte tinha já investido largamente na educação depois da Guerra, e se encontrava em declínio demográfico. Daí que tais regulamentos não contemplem subsídios a acções que se enquadram no horizonte dos sistemas educativos formais. O essencial deste programa consiste em mostrar que, dada a especificidade do atraso educativo português, não faz sentido dispender grandes somas noutros sectores sem que os sistemas educativo e formativo estejam preparados para dar uma formação adequada a todos os portugueses: eficiente, moderna e de qualidade." (Gabinete de Estudos e Planeamento/Ministério da Educação, 1990: 20; sublinhados nossos). 
dade", como a análise efectuada indica, longe de se apresentar como homogénea e internamente coerente, afigura-se antes como um processo caracterizado tanto pelas articulações emergentes como pelas discrepâncias e singularidades e marcado pelas circunstâncias bem como pelas vicissitudes de outros processos em curso. Nesse sentido, o primeiro Programa de Desenvolvimento Educativo para Portugal (1990-1993) torna-se possível e permite investir fortemente em alguns sectores e vertentes do sistema de ensino, não por via de uma política educativa explicitamente definida na Comunidade/União Europeia, mas com base em prioridades políticas de outro âmbito; estas adquirem uma influência acrescida, permitindo ou beneficiando selectivamente a eleição de alvos ou orientações que claramente intersectam e condicionam a elaboração das políticas educativas nacionais. A política de coesão social da Comunidade articulada com a valorização da qualificação dos recursos humanos, entendida como ensino/formação profissional pós-obrigatória, com particular atenção à população jovem, são as bases políticas e ideológicas que fundamentam a elaboração da proposta do PRODEP e a sua aprovação pelas instâncias comunitárias.

O que parece ser possível concluir, a partir da análise do processo de criação do subsistema de Escolas Profissionais, em Portugal, em 1989, é:

(i) por um lado, a importância decisiva de considerar as relações entre a elaboração das políticas educativas nacionais e as prioridades e políticas comunitárias, enquanto contexto relevante e incontornável para a adequada compreensão daquelas;

(ii) por outro lado, que tais interacções e (inter)dependências - apresentando certamente configurações e intensidades muito distintas, conforme o sector considerado - parecem, no que toca à educação, assumir o relevo de elementos ou factores condicionantes, potenciando ou subalternizando determinadas opções, mas de modo nenhum podem ser vistas como determinando a forma concreta ou o sentido da política adoptada.

Fica, assim, lugar para sublinhar articulações entre as políticas nacionais e comunitárias - caracterizáveis, na análise efectuada, como de indução, reforço ou viabilização, harmonização ou congruência e inibição - identificando simultaneamente o modo específico e, por vezes, singular como medidas referenciáveis a processos de europeização são configuradas e concretizadas no contexto nacional. 


\subsubsection{A recontextualização de políticas comunitárias e a europeização de políticas educativas nacionais}

Torna-se agora necessário discutir e confrontar as perspectivas decorrentes das análises realizadas. Nesse sentido, afirmamos ser possível defender que, nomeadamente a partir de 1986, está em curso o processo de europeização da educação no contexto comunitário. Mas é também verificável que, quer a criação do subsistema de Escolas Profissionais, quer o PRODEP, que assume um papel decisivo na viabilização daquela iniciativa, são (relativamente) exteriores às medidas de intervenção política comunitária no domínio da educação em vigor naquela época, assentes no desenvolvimento de Programas de Acção cuidadosamente fundamentados em prioridades oriundas de outras esferas legítimas de actuação e influência da Comunidade Europeia (cf. Antunes, 1999a). ${ }^{24}$

Neste contexto, deve ser realçada a ambiguidade que caracteriza esta medida de política educativa. Por um lado, representa uma intervenção clara no sistema de ensino português e participa da reestruturação do nível de escolarização secundária; por outro lado, a sua elaboração inscreve-se formalmente em políticas comunitárias no domínio da formação profissional e não da educação. Nessa medida, estamos confrontados com processos políticos cuja articulação se afigura controversa e complexa. Se a dinâmica de europeização da educação está em curso na época em análise, o âmbito de actuação da Comunidade parece assumir contornos que não coincidem estritamente com aqueles que decorrem da definição de agendas comuns e políticas comunitárias com incidência no campo considerado. E esta seria a segunda conclusão a retirar do estudo realizado. A análise efectuada evidencia, assim, um processo de europeização baseado na expansão do alcance de prioridades e políticas comunitárias para domínios conexos susceptíveis de lhes serem referenciados, tanto no plano nacional como no comunitário.

Assim, o estudo realizado permite retirar uma terceira conclusão: as dinâmicas de europeização identificáveis no domínio da educação não se limitam apenas àquelas que têm como ponto de origem as iniciativas de instâncias comunitárias. Também um, ou alguns, Estados-membros são

\footnotetext{
${ }^{24}$ Consideram-se em tais condições os programas: COMETT (Programa de cooperação entre a universidade e a empresa em matéria de formação no domínio das tecnologias); ERASMUS (Programa de cooperação das Comunidades Europeias para a mobilidade dos estudantes universitários); PETRA (Programa de acção para a formação profissional e preparação dos jovens para vida adulta e profissional); DELTA (Acção comunitária no domínio das tecnologias educativas, desenvolvimento do ensino europeu através do processo tecnológico; e LINGUA (Programa de acção para a promoção do conhecimento de línguas estrangeiras na Comunidade Europeia).
} 
susceptíveis de desencadear processos de expansão (que pode ser conjuntural e sui generis) da esfera de actuação da Comunidade, recontextualizando políticas comunitárias de âmbito distinto, delas derivando e a elas referenciando medidas e formas de intervenção em áreas definidas como de exclusiva competência nacional. No caso em análise, o Estado português mobilizou esta modalidade de produção de processos de europeização, concorrendo para a instabilização e rarefacção das fronteiras entre os domínios de intervenção nacional e comunitária.

Podemos, desse modo, identificar, nomeadamente no período compreendido entre 1986 e 1992, o que consideraríamos como três modalidades de produção de processos de europeização das políticas educativas nacionais:

(i) a definição de agendas e prioridades comuns aos Estados-membros, na esfera da educação;

(ii) o estabelecimento de uma agenda e uma política comunitárias para a educação;

(iii) a recontextualização de políticas comunitárias.

Se os primeiros dois tipos de processos mencionados são iniciados em instâncias comunitárias e tenderão a produzir consequências no conjunto dos países envolvidos, a terceira modalidade referida tem origem num dado Estado-membro, que será provavelmente o principal implicado nos efeitos desencadeados. Por outro lado, estes constituem alguns dos processos que contribuem para a forma concreta e específica assumida pela agenda política nacional para a educação; aquela configuração é devedora das dinâmicas e relações globais que a estruturam, em que está incluído o conjunto de mediações construídas ao nível da Comunidade/União Europeia (as opções, as políticas, as prioridades, as instituições).

\section{Ainda a especificidade educativa portuguesa: a agenda política nacional para a educação}

A análise da criação do subsistema de Escolas Profissionais torna possível sinalizar alguns vectores do que designamos como a agenda política nacional para a educação elaborada e promulgada num período que entendemos compreendido entre 1988 e 1993 . Assumimos que este conjunto de problemas, soluções e expectativas é estruturado por processos globais cujas recepção e interpretação são específicas num dado contexto nacional. A reacção àquelas dinâmicas depende, assim, quer dos constrangimentos, 
quer dos recursos sócio-institucionais que, numa dada conjuntura, se afirmam como efectivamente actuantes. ${ }^{25}$

A crise e consolidação do Estado-providência e da escola de massas (Santos, 1990; Stoer e Araújo, 1992), o processo de Reforma do Sistema Educativo levado a cabo através de um conjunto de medidas de política educativa integrantes da orientação de neoliberalismo educacional mitigado que marcou a acção governativa na época em questão (Afonso, 1998) constituem dinâmicas sócio-políticas que definem o contexto em que têm lugar os processos que analisámos.

Em Portugal, as transformações globais que conduziram à forma de actuação como Estado de competição convergiram com dinâmicas sócio-políticas que tornaram imperativa a expansão dos serviços educativos, no sector de ensino/formação de nível secundário, exigida, disputada e submetida a pressões contraditórias por parte de distintos grupos e sectores sociais. ${ }^{26}$ Estava-se perante uma situação atravessada por dilemas e tensões cuja gestão foi tentada através de medidas que concorreram simultaneamente para a ampliação e a fragilização da cidadania educativa. A ampliação da cidadania é promovida porque o acesso a percursos de escolarização prolongada e à certificação de nível secundário é alargado através da criação do subsistema de Escolas Profissionais (e do Sistema de Aprendizagem, nível III). A fragilização do usufruto desse direito por uma significativa parte da população decorre do carácter particularista (Dale e Ozga, 1993) daquelas políticas que, longe de concorrer para a generalização de um dado nível de bens e serviços de valor social e educativo equivalente, posicionam e estratificam os seus beneficiários. A fragilização da cidadania resulta ainda da segmentação institucional que corporizou a provisão de tais serviços e do carácter privado assumido pelo subsistema de Escolas Profissionais. Isto porque, neste caso, não só não é fornecido um serviço educativo com valor social equivalente, como não é usufruído em condições de paridade com os beneficiários do ensino regular.

As transformações sofridas pelo Estado-providência - que em Portugal nunca chegou a ser consolidado - em resultado das dinâmicas económico-políticas que colocaram o apoio ao processo de acumulação no topo da agenda do Estado saldaram-se, no que toca às políticas para o ensino/for-

${ }^{25}$ Uma análise mais desenvolvida das questões e dos processos sociais aqui discutidos pode ser encontrada em Antunes, 2004.

26 Deve ser salientado que, nesta época, em Portugal, de uma forma não verificável em outros países europeus e ocidentalizados, convergiram múltiplas pressões para a expansão dos serviços educativos em todos os níveis do sistema, desde a educação de infância ao ensino superior (cf. Vilarinho, 2000; Afonso, 1998; Seixas, 2001). 
mação de nível secundário no final dos anos oitenta, por medidas que procuraram responder a pressões contraditórias oriundas quer do imperativo de actuar em benefício da competitividade da economia nacional, quer das lutas e exigências conflituais de distintos grupos sociais no que toca à reivindicação da expansão do ensino secundário. O subsistema de Escolas Profissionais, como inovação sócio-política particularmente ilustrativa neste domínio, caracteriza-se por essa duplicidade.

Esta iniciativa foi ainda orientada pela preocupação de promover mudanças na educação desejavelmente congruentes com as alterações verificadas nos sistemas educativo e de emprego. As opções neste domínio privilegiaram a criação de modalidades de escolarização (e de formação) que contemplavam orientações e/ou dispositivos destinados a favorecer quer a gestão da inserção profissional pelas instituições de formação, quer a mobilização e socialização profissionais. Esta foi a resposta encontrada para a crise de emprego dos jovens e as profundas alterações ocorridas na relação salarial em que aqueles viriam a estar envolvidos. Também a recontextualização da educação $0^{27}$ relativamente ao mundo e às instituições produtivos e de trabalho assumiu entre nós o carácter de um imperativo algo paradoxal: a perda do direito ao emprego constituiu, para muitos dos jovens portugueses, o corolário contraproducente do usufruto do direito à educação. A formação de nível secundário, que agora se desenha integrando orientações e dispositivos voltados para a socialização e a inserção profissionais, é susceptível de se tornar, para os grupos sociais que, pela primeira vez, encaram a expectativa de a ela aceder, um sucedâneo mais que imperfeito para o emprego (e as condições de emprego) provavelmente imprevisível quando não inacessível.

A agenda reformista corporizada pela criação do subsistema de Escolas Profissionais aparece como um exemplo emblemático de algumas das transformações sofridas pelo Estado-providência nas últimas décadas. O ensaio de novos arranjos institucionais contribuiu para diluir o carácter estatal e público da educação, redistribuindo responsabilidades na gestão da sua provisão e redefinindo o conjunto de actores e entidades que legitimamente participam na sua produção e os respectivos papéis no conjunto do processo. Os promotores, o contrato-programa e a associação em parceria foram os instrumentos que permitiram a edificação da combinação institucional que caracterizou aquele subsistema em que o financiamento, fornecimento e a regulação dos serviços prestados são coordenados segundo formas que relevam do Estado, do Mercado e do Terceiro Sector. Consideramos, por isso,

${ }^{27}$ Esta expressão é inspirada na análise desenvolvida em Moore (1987). 
que esta iniciativa política configura uma forma de actuação como Estado-articulador favorável não só à emergência de outros actores e interesses sociais como à procura de novas regras para o seu confronto e mediação. É notório que, numa iniciativa sem precedentes, o Estado dinamizou e se envolveu activamente na criação de todo um subsistema de ensino que é, em regra, privado. A invenção de novas modalidades de provisão de serviços sociais - que permitissem redefinir campos de acção, protagonistas e responsabilidades, a natureza dos bens e serviços, do contrato social que os sustenta e a relação preconizada com os seus beneficiários bem como o estatuto destes - foi o projecto lançado, e, em boa medida, concretizado, através desta medida de política educativa. ${ }^{28}$

Assim, os problemas confrontados pelo Estado português - em que a prioridade à competitividade nacional e ao processo de acumulação se conjugou com pressões sociais contraditórias relacionadas com a expansão dos serviços educativos - criaram as condições para a gestação de uma inovação política em que se combinam, de modo específico, as formas de actuação como Estado de competição e como Estado-articulador. A modalidade de provisão de bem-estar assim gerada é marcada pela tendência para ampliar o domínio do privado como locus de promoção do bem comum; neste processo é o próprio modelo de provisão de serviços educativos que é alterado. A dinâmica gerada é, no entanto, suficientemente heterogénea e ambivalente para sugerir que formas inovadoras de promoção da coesão com justiça social podem também ter sido experimentadas.

\section{Notas de síntese: a estruturação global de uma inovação nacional}

A União Europeia, organização regional em que Portugal se integra, constitui uma obra dos Estados que, dessa forma, se dotam de capacidades de simultaneamente promoverem e reagirem a processos de globalização para cujos efeitos contribuem mas que são imunes ao seu controlo isoladamente. A perspectiva de que as mudanças que vivemos se traduzem através de uma agenda globalmente estruturada para a educação explorou o modo como a União Europeia se constitui em instância de mediação de algumas dessas transformações em curso. É assim que os processos de europeização e de formação de um referencial global para as políticas públicas no contexto comunitário constituem modalidades particulares de produção e recepção dos efeitos de globalização nos países membros da União Europeia.

\footnotetext{
${ }_{28}$ Para um estudo detalhado deste processo consultar Antunes $(2001,2004)$; para uma análise das alterações do papel do Estado identificáveis no contexto das políticas educativas cf. Afonso (2001).
} 
Estas dinâmicas obtêm importantes consequências na educação através do seu impacto no modo de regulação, e nas formas de actuação do Estado que lhe estão associadas; assim, os processos acima referidos representam os modos como tais mudanças são veiculadas e modeladas por relações específicas que têm lugar entre os Estados e instituições nacionais e as instâncias comunitárias. Tais movimentos revelaram-se decisivos para a estruturação de uma agenda para a educação em que se inscreve a criação do subsistema de Escolas Profissionais em Portugal em 1989.

A análise desta inovação sócio-política permitiu questionar agora as relações entre a elaboração de uma medida de política educativa nacional e o contexto comunitário. Assim, a configuração desta medida evidencia quer o modo como a Comunidade/União Europeia se constitui como mediação, veículo e autor de processos de globalização, quer as formas pelas quais o Estado português interpretou, aceitou, traduziu e reagiu aos constrangimentos e recursos com que, naquele contexto, se confrontava.

Nesta fase da reflexão teórica e da pesquisa empírica sobre tais questões, pensamos ser possível fazer um balanço do estudo realizado através de duas notas de síntese. Em primeiro lugar, defendemos que são visíveis processos de interpenetração entre a elaboração da medida de implementação das Escolas Profissionais em Portugal e opções, prioridades de intervenção e políticas comunitárias: a possibilidade de integração de um Programa de Desenvolvimento Educativo para Portugal nos objectivos e políticas orientados para a coesão social da Comunidade Europeia, com base na qualificação de recursos humanos, permitiu a viabilização (nomeadamente financeira) de um projecto de ensino profissional a que não é alheia a motivação induzida por um intenso investimento comunitário na formação pós-obrigatória dos jovens. Nesse sentido, poder-se-ia falar da presença de vectores de europeização das políticas educativas portuguesas, nomeadamente segundo uma modalidade específica que implicou a recontextualização, com alteração de âmbito, de políticas comunitárias. Por outro lado, sugerimos que é possível identificar, no processo de criação do subsistema de Escolas Profissionais, a incorporação de tendências, congruentes com orientações e normas de acção, emergentes ao nível da Comunidade Europeia, quanto à elaboração das políticas (educativas) públicas: uma agenda voltada para a redefinição da educação frente à produção e ao mundo privado, para a reconfiguração da cidadania educativa e para a fundação de novas modalidades de articulação das instituições educativas no contexto comunitário. Nesta perspectiva é possível argumentar a favor da consideração de dinâmicas de convergência das políticas educativas portuguesas no contexto comunitário, sinalizando a formação de um referencial global que influencia o 
modo como actores e decisores concebem e realizam a intervenção política pública em educação.

Desta forma, a criação do subsistema de Escolas Profissionais em Portugal em 1989 constitui uma inovação modelada no contexto de uma agenda política nacional para a educação que é globalmente estruturada não só porque se inscreve no conjunto de problemas - produzidos e/ou condicionados por fenómenos globais - com que o Estado português se confronta(va), como porque as respostas seleccionadas são igualmente enquadradas e delimitadas por relações (económicas, políticas e ideológicas) globais. Assim, a articulação de políticas nacionais e comunitárias (europeização) e a promoção ou reforço de um referencial global europeu para a intervenção pública em educação contribuem de modos específicos para a configuração de uma agenda globalmente estruturada nesta área. No caso da criação do subsistema de Escolas Profissionais em Portugal, aquele contributo, que se tornou visível ao longo do estudo que apresentámos, consistiu sobretudo em disponibilizar modelos, quer de definição de problemas, quer de construção de respostas, e em proporcionar meios e instrumentos de acção para a intervenção pública, selectivamente orientados para tais opções e prioridades.

Por outro lado, sublinhamos ainda que a configuração assumida pela inovação em análise é desenhada, quer pelos processos referidos, quer por problemas, recursos, expectativas e reivindicações salientes no contexto nacional no respeitante ao sistema educativo e ao ensino secundário: a ampliação e fragilização da cidadania educativa, a recontextualização da educação frente ao mundo produtivo e de trabalho, o ensaio de novas modalidades de provisão da educação convergem para definir os contornos de uma medida de política educativa indubitavelmente inscrita, como se procurou mostrar, nas condições, desafios e soluções que marcavam a realidade educativa portuguesa.

\section{Referências Bibliográficas}

Afonso, Almerindo Janela (1998), Políticas educativas e avaliação educacional. Para uma análise sociológica da reforma educativa em Portugal (1985-1995). Braga: Universidade do Minho.

Afonso, Almerindo Janela (2001), "A redefinição do papel do Estado e as políticas educativas: elementos para pensar a transição", Sociologia. Problemas e Práticas, 37, 33-48. Aglietta, Michel (1997), Régulation et crises du capitalisme. Paris: Éditions Odile Jacob. Andersen, Svein S.; Eliassen, Kjell A. (1993a), "The EC as a New Political System”, in Svein S. Andersen; Kjell A.Eliassen (orgs.), Making Policy in Europe: The Europeification of National Policy-Making. London: Sage, 3-18. 
Andersen, Svein S; Eliassen, Kjell A. (1993b), "Policy-Making in the New Europe”, in Svein S. Andersen; Kjell A.Eliassen (orgs), Making Policy in Europe: The Europeification of National Policy-Making. London: Sage, 255-263.

Antunes, Fátima (1998), Políticas educativas para Portugal, anos 80/90. O debate acerca do ensino profissional na escola pública. Lisboa: Instituto de Inovação Educacional. Antunes, Fátima (1999a), "A Comunidade/União Europeia e a transnacionalização da educação: elementos para debate”, in Albano Estrela; Júlia Ferreira (orgs.), Educação e política. Actas do II Congresso Internacional da AIPELF/AFIRSE. $2^{\circ} \mathrm{vol}$. Lisboa: AFIRSE Portuguesa/ Faculdade de Psicologia e Ciências da Educação, 855-868.

Antunes, Fátima (1999b), "Orientações e mudanças para a educação no contexto comunitário: alguns elementos e breves anotações, in AAVV, Investigar e formar em educação. Actas do IV Congresso da SPCE. $1^{\circ}$ vol. Porto: Sociedade Portuguesa de Ciências da Educação, 399-412.

Antunes, Fátima (2000a), "Novas diferenciações e formas de governação em educação: o processo de criação das Escolas Profissionais em Portugal”, Revista Brasileira de Política e Administração da Educação, 16(1), 31-45.

Antunes, Fátima (2000b), "Novas instituições e processos educativos. A reforma portuguesa do ensino secundário no contexto comunitário (1988-1996)”, in José Augusto Pacheco (org.), Políticas educativas. O neoliberalismo em educação. Porto: Porto Editora, 109-134.

Antunes, Fátima (2001), "Os locais das escolas profissionais: novos papéis para o Estado e a europeização das políticas educativas”, in Stephen Ronald Stoer et al. (orgs.), Transnacionalização da educação. Da crise da educação à "educação" da crise. Porto: Afrontamento, 163-208.

Antunes, Fátima (2003), "Novas modalidades de provisão da educação: o subsistema de escolas profissionais em Portugal”. Comunicação apresentada ao II Congresso do Forum Português de Administração Educacional, "A escola entre o Estado e o mercado: o público e o privado na regulação da educação”. Lisboa, 15-17 de Maio de 2003 (texto policopiado).

Antunes, Fátima (2004), Políticas educativas nacionais e globalização. Novas instituições eprocessos educativos. O subsistema de Escolas Profissionais em Portugal (1987-1998). Braga: Universidade do Minho.

Apple, Michael W. (1996), "Power, Meaning and Identity: Critical Sociology of Education in the United States", British Journal of Sociology of Education, 17(2), 125-144.

Beukel, Erik (1993), "Education”, in Svein S. Andersen; Kjell Eliassen (orgs), Making Policy in Europe: The Europeification of National Policy-Making. London: Sage, 155-170.

Boyer, Robert (1987), La théorie de la régulation: une analyse critique. Paris: La Découverte. 
Boyer, Robert (1997), "How Does a New Production System Emerge?”, in R. Boyer; Jean-Paul Durand, After Fordism. London: Macmillan, 1-63.

Castells, Manuel (1997), The Information Age: Economy, Society and Culture, Vol. II, The Power of Identity. Oxford: Blackwell.

Castells, Manuel (1998), The Information Age: Economy, Society and Culture, Vol. III, End of Millennium. Oxford: Blackwell.

Cerny, Philip G. (1990), The Changing Architecture of Politics. Structure, Agency and the Future of the State. London: Sage.

Dale, Roger (1988), “A educação e o estado capitalista: contribuições e contradições”, Educação e Realidade, 13(1), 17-37.

Dale, Roger (1997), "The State and the Governance of Education: An Analysis of the Restructuring of the State-Education Relationship”, in A. H. Halsey et al. (orgs.), Education - Culture, Economy and Society. New York: Oxford UP, 273-282.

Dale, Roger (1999), "Specifying Globalization Effects on National Policy: A Focus on the Mechanisms”, Journal of Education Policy, 14(1), 1-17.

Dale, Roger (2000a), "Globalization: A New World for Comparative Education?", in Jurgen Schriewer (org.), Discourse Formation in Comparative Education. Berlin: Peter Lang, 87-109.

Dale, Roger (2000b), "Globalization and Education: Demonstrating a 'Common World Educational Culture' or Locating a 'Globally Structured Educational Agenda'?”, Educational Theory, 50(4), 427-448.

Dale, Roger; Ozga, Jenny (1993), “Two Hemispheres - Both 'New Right'?: 1980's Education Reform in New Zealand and England and Wales", in Bob Lingard et al. (orgs.), Schooling Reform in Hard Times. London: Falmer Press, 63-87.

Dale, Roger; Robertson, Susan (2000), "Regional Organizations as a Medium of Globalization of Education". Comunicação apresentada ao workshop sobre "Reflecting Globalization Effects on National Education Policy: The Perspective from East Asia”. City University of Hong Kong, Setembro de 2000 (texto policopiado).

Gabinete de Estudos e Planeamento/Ministério da Educação (1990), PRODEP - Programa de Desenvolvimento Educativo para Portugal, 1990-1993. PRODEP com contribuição comunitária. Lisboa: GEP/ME.

Giddens, Anthony (1992), As consequências da modernidade. Oeiras: Celta.

Giddens, Anthony (2000), O mundo na era da globalização. Lisboa: Presença.

Gomes, Rui M. (2001), "A globalização da escola de massas: perspectivas institucionalistas e genealógicas”, Revista Crítica de Ciências Sociais, 61, 135-167.

Grácio, Sérgio (1998a), Ensinos técnicos e política em Portugal, 1910-1990. Lisboa: Instituto Piaget.

Grácio, Sérgio (1998b), "Ensino privado em Portugal. Contributos para uma discussão", Sociologia - Problemas e Práticas, 27, 129-153. 
Lima, Licínio C. (1998), "A administração do sistema educativo e das escolas (1986-1996)", in AAVV, A evolução do sistema educativo e o PRODEP. Estudos temáticos. Lisboa: Ministério da Educação/Departamento de Avaliação, Prospectiva e Planeamento, 15-96.

Marques, Margarida (1993), O modelo educativo das Escolas Profissionais: um campo potencial de inovação. Lisboa: Educa/Associação Nacional de Escolas Profissionais.

Meyer, John et al. (1992), School Knowledge for the Masses: World Models and National Primary Curricular Categories in the Twentieth Century. London: The Falmer Press.

Mény, Yves et al. (orgs.) (1995), Politiques publiques en Europe. Paris: L'Harmattan.

Moore, Robert (1987), "Education and the Ideology of Production”, British Journal of Sociology of Education, 8(2), 227-242.

Nóvoa, António (1998), Histoire E comparaison (essais sur l'éducation). Lisboa: Educa.

Ramirez, Francisco; Boli, John (1987), "The Political Construction of Mass Schooling: European Origins and Worldwide Institutionalization", Sociology of Education, 60, 2-17.

Rodríguez, Víctor (1993), “De Roma a Maastricht: 35 años de cooperación comunitária en educación”, Revista de Educación, 301, 7-24.

Rose, José (1984), En quête d'emploi. Formation, chômage, emploi. Paris: Economica.

Rose, José (1996), "L'organisation des transitions professionnelles entre socialisation, mobilisation et recomposition des rapports de travail et d'emploi", Sociologie $d u$ Travail, 1, 63-79.

Santos, Boaventura de Sousa (1990), O estado e a sociedade em Portugal (1974-1988). Porto: Afrontamento.

Santos, Boaventura de Sousa (1997), "Por uma concepção multicultural de direitos. Humanos”, Revista Crítica de Ciências Sociais, 48, 11-32.

Santos, Boaventura de Sousa (1998), Reinventar a democracia. Lisboa: Fundação Mário Soares/Gradiva.

Santos, Boaventura de Sousa (1999), A reinvenção solidária e participativa do estado, Oficina do CES 134.

Santos, Boaventura de Sousa (2001a), "Os processos de globalização”, in Boaventura de Sousa Santos (org.), Globalização: fatalidade ou utopia?. Porto: Afrontamento, 31-106.

Schriewer, Jürgen (1996), "Sistema mundial y redes de interrelación: la internacionalización de la educación y el papel de la investigación comparada”, in Miguel A. Pereyra et al. (orgs.), Globalización y descentralización de los sistemas educativos. Fundamentos para um novo programa de la educación comparada. Barcelona: Ediciones Pomares-Corredor, 17-58.

Seixas, Ana Maria (2001), "Políticas educativas para o ensino superior: a globalização neoliberal e a emergência de novas formas de regulação estatal”, in Stephen Ronald Stoer et al. (orgs.), Transnacionalização da educação. Da crise da educação à "educação" da crise. Porto: Afrontamento, 209-238. 
Soysal, Yasemin N. (1993), "Immigration and the Emerging European Polity", in Svein S. Andersen; Kjell Eliassen (orgs.), Making Policy in Europe: The Europeification of National Policy-Making. London: Sage, 171-186.

Stoer, Stephen Ronald et al. (1990), "O novo vocacionalismo na política educativa em Portugal e a reconstrução da lógica da acumulação”, Revista Crítica de Ciências Sociais, 29, 11-53.

Stoer, Stephen Ronald; Araújo, Helena (1992), Escola e aprendizagem para o trabalho num pais da (semi)periferia europeia. Lisboa: Escher.

Teodoro, António (2001a), "Organizações internacionais e políticas educativas nacionais: a emergência de novas formas de regulação transnacional, ou uma globalização de baixa intensidade", in Stephen Ronald Stoer et al. (orgs.), Transnacionalização da educação. Da crise da educação à "educação" da crise. Porto: Afrontamento, 125-161.

Teodoro, António (2001b), A construção política da educação. Estado, mudança social e políticas educativas no Portugal contemporâneo. Porto: Afrontamento.

Vilarinho, Maria Emília (2000), Políticas de educação pré-escolar em Portugal (1977-1997). Lisboa: Instituto de Inovação Educacional. 